\title{
LA EXTINCIÓN JUDICIAL DE LOS PARTIDOS POLÍTICOS INACTIVOS: UNA INADVERTIDA NOVEDAD DE LA LEY ORGÁNICA 3/2015, DE 30 DE MARZO
}

\author{
The judicial extinction of inactive political parties: \\ An unnoticed novelty of the Ley Orgánica 3/2015, \\ of March $30^{\text {th }}$
}

\author{
MIQUEL PONS-PORTELLA \\ Universitat Oberta de Catalunya \\ m_p_portella@hotmail.com
}

Cómo citar/Citation

Pons-Portella, M. (2017)

La extinción judicial de los partidos políticos inactivos: una inadvertida novedad de la Ley Orgánica 3/2015, de 30 de marzo. Revista Española de Derecho Constitucional, 110, 165-184. doi: https://doi.org/10.18042/cepc/redc.110.06

\section{Resumen}

El procedimiento para la declaración judicial de extinción de los partidos políticos que se encuentren en situación de inactividad es una de las muchas novedades introducidas por la Ley Orgánica 3/3015, de 30 de marzo, de Control de la Actividad Económico-financiera de los Partidos Políticos, en el texto de la Ley Orgánica 6/2002, de 27 de junio, de Partidos Políticos. Se trata de un mecanismo de «depuración» del Registro de Partidos Políticos cuyo conocimiento se atribuye a la jurisdicción contenciosa-administrativa con el objetivo de garantizar plenamente el derecho fundamental de asociación. En las siguientes páginas, se aborda el estudio de esta nueva institución, tanto materialmente como procedimentalmente, poniendo especial énfasis en aquellos aspectos de la nueva regulación cuya aplicación práctica puede plantear mayores interrogantes.

\section{Palabras clave}

Partidos políticos; Registro de Partidos Políticos; derecho de asociación; jurisdicción contenciosa-administrativa. 


\section{Abstract}

The procedure for the judicial declaration of extinction of political parties in a situation of inactivity is one of the many innovations introduced by the Ley Orgánica $3 / 2015$, of March $30^{\text {th }}$, on control of the economic and financial activity of Political Parties, to the text of Ley Orgánica 6/2002, of June 27 ${ }^{\text {th }}$, on Political Parties. It is a mechanism of "cleansing" the Register of Political Parties whose knowledge is attributed to the contentious-administrative jurisdiction in order to fully guarantee the fundamental right of association. This review deals with the study of the new institution, both materially and procedurally, with particular emphasis on those aspects of the new regulation which may pose greater practical application questions.

\section{Keywords}

Political parties; Register of Political Parties; right of association; contentious-administrative jurisdiction. 


\section{SUMARIO}

I. INTRODUCCIÓN. II. LA TRAMITACIÓN PARLAMENTARIA DEL NOVÍSIMO ART. 12 BIS LOPP. III. LA INACTIVIDAD DEL PARTIDO POLÍTICO: LOS TRES «MOTIVOS» DE EXTINCIÓN DEL ART. 12 BIS.1 LOPP: 1. Falta de adaptación de los estatutos del partido. 2. Ausencia de renovación de los órganos de gobierno y representación del partido durante ocho años. 3. Falta de presentación de las cuentas anuales del partido. IV. EL PROCEDIMIENTO PARA LA DECLARACIÓN JUDICIAL DE EXTINCIÓN DE PARTIDOS POLÍTICOS: 1. Legitimación activa: 1.1. El Ministerio del Interior y el Registro de Partidos Políticos. 1.2. La iniciación «a instancia de los interesados». 1.3. El Ministerio Fiscal. 2. Órgano jurisdiccional competente. 3. El apercibimiento del art. 12 bis. 2 LOPP. 4. Tramitación procesal. 5. Efectos de la sentencia. V. EL ART. 12 BIS LOPP EN EL TIEMPO: ANÁLISIS DE LA DISPOSICIÓN TRANSITORIA PRIMERA DE LA LEY ORGÁNICA 3/2015. VI. CONCLUSIONES. BibLIOGRAFía.

\section{INTRODUCCIÓN}

Pese a que el preámbulo de la Ley Orgánica 3/2015, de 30 de marzo, de Control de la actividad Económico-financiera de los Partidos Políticos, se refiere a él como una «novedad de enorme trascendencia práctica», el flamante procedimiento para la declaración judicial de extinción de un partido político ha pasado desapercibido en medio de la marabunta legislativa con la que finalizó la X Legislatura. De hecho, la propia Ley Orgánica 3/2015 incluye una tal cantidad de reformas — tanto en la Ley Orgánica 6/2002, de 27 de junio (LOPP); como en la Ley Orgánica 8/2007, de 4 de julio, sobre Financiación de los Partidos Políticos (LOFPP) — que es ciertamente comprensible que el novísimo art. 12 bis de la aludida LOPP haya merecido poca atención ${ }^{1}$.

La relevancia de este, sin embargo, es de enjundia. En efecto, si hasta la entrada en vigor de la Ley Orgánica 3/2015, los partidos políticos solamente podían cesar en su vida jurídica por disolución — voluntaria o forzosa—o por

1 Un buen ejemplo al respecto lo ofrece Sánchez Muñoz (2015). La doctrina, en efecto, ha dado prioridad al estudio del contenido económico-financiero de la Ley Orgánica $3 / 2015$, por lo que la bibliografía que podemos mencionar sobre el asunto que nos ocupa se limita a obras generales anteriores como Bautista Plaza (2006), Martínez-Cuevas (2006), Montilla Martos (2004), Pérez-Moreno Agapito (2007) y Tajadura Tejada (2004). 
suspensión, a partir de aquella fecha se añade una nueva causa: la extinción ${ }^{2}$. Su finalidad es, según leemos en el preámbulo de la propia Ley Orgánica $3 / 2015$, lograr «la depuración del registro de partidos, en el que figuran inscritos varios miles, en una gran mayoría inactivos».

Así pues, lo que determina la extinción de un partido político es su «inactividad», la cual se presume únicamente en los tres supuestos que establece el art. 12 bis.1 LOPP. La apreciación de tal inactividad corresponde, mediante el procedimiento regulado en el mismo precepto, a los órganos de la jurisdicción contenciosa-administrativa, por lo que la Ley Orgánica 3/2015 también ha tenido que operar, como veremos, varias modificaciones en el texto de la Ley 29/1998, de 13 de julio, reguladora de la Jurisdicción Contencioso-administrativa (LJCA).

\section{LA TRAMITACIÓN PARLAMENTARIA DEL NOVÍSIMO ART. 12 BIS LOPP}

El Proyecto de Ley Orgánica de Control de la Actividad Económico-financiera de los Partidos Políticos, presentado en febrero de 2014 por el Gobierno ante el Congreso de los Diputados ${ }^{3}$, no preveía la inclusión de un nuevo art. 12 bis en la LOPP.

El precepto tiene su origen en la enmienda núm. 204 presentada por el Grupo Parlamentario Popular en el Congreso con la siguiente justificación:

Esta disposición obedece a la necesidad de clarificar la situación actual del Registro de Partidos Políticos. A día de hoy hay aproximadamente 4.200 partidos inscritos en el Registro, en una gran mayoría inactivos. Este hecho, unido a que la cancelación de las inscripciones en el Registro solo cabe cuando haya una sentencia judicial firme recaída en el orden jurisdiccional penal en tal sentido o por decisión del partido, ha impulsado esta modificación normativa en la que se prevé que a los partidos políticos que no adecuen sus estatutos a lo previsto en la ley en el plazo fijado o que no presenten sus cuentas anuales al Tribunal de Cuentas

2 Al respecto es muy elocuente el cambio de redactado del art. 4.4 LOPP. En su versión original, esta disposición estipulaba que «la inscripción en el Registro producirá efectos indefinidamente mientras no se anote en el mismo su suspensión o disolución, bien por notificación de la decisión acordada por el propio partido de acuerdo con las previsiones estatutarias, bien por ser declarado judicialmente ilegal y disuelto o suspendido». Tras la Ley Orgánica 3/2015, se añade al art. 4.4 el siguiente inciso final: «o por ser declarado judicialmente extinguido de acuerdo con lo previsto en el artículo 12 bis».

3 Boletin Oficial de la Cortes Generales, Congreso de los Diputados, núm. A-82-1, 28.02.2014, pp. 1-17. 
durante un número determinado de años, se les aplique un procedimiento de declaración de extinción de carácter judicial, es decir, con todas las garantías.

Esta propuesta de cambio del Proyecto de Ley Orgánica también supuso la presentación, por parte del mismo grupo parlamentario, de las enmiendas núms. 193, 197, 198, 200, 203, 205, 206 y $209^{4}$ con el fin de adaptar varios artículos de la LOPP y de otras disposiciones legales afectadas.

Como venimos diciendo, el nuevo procedimiento del art. 12 bis LOPP tiene como finalidad primordial lograr, en palabras del preámbulo de la Ley Orgánica 3/2015, la «depuración» y la «mejora del funcionamiento del Registro de Partidos Políticos» mediante la cancelación judicial de «la inscripción registral de [los] partidos que, en atención a las circunstancias que se contemplan, se consideran inactivos». De este modo, el nuevo mecanismo también debiera actuar como incentivo para que todos los partidos cumplan con sus obligaciones legales más esenciales, muchas de las cuales traen causa de la propia reforma que opera la Ley Orgánica 3/2015.

En este sentido, cabe reseñar que la redacción del art. 12 bis.1 LOPP, según la enmienda núm. 204, solo contemplaba dos causas de extinción, a saber: la falta de adaptación de los estatutos y la falta de presentación de las cuentas anuales. Fue durante la tramitación parlamentaria, ante la Comisión Constitucional del Congreso ${ }^{5}$, cuando se añadió el tercer motivo de extinción - es decir, la ausencia de renovación de los órganos de gobierno y representación del partido durante ocho años- que ahora se halla previsto en el apdo. b) del precepto de referencia.

\section{LA INACTIVIDAD DEL PARTIDO POLÍTICO: LOS TRES «MOTIVOS» DE EXTINCIÓN DEL ART. 12 BIS.1 LOPP}

La declaración judicial de extinción de un partido político - $-\mathrm{y}$, por lo tanto, la cesación de toda su eficacia — procede, única y exclusivamente, de la

Ibid., pp. 153-155 y 157-165.

5 Diario de Sesiones, Congreso de los Diputados (Comisiones), núm. 733, 14.01.2015, pp. 14-15. El diputado José Antonio Bermúdez de Castro, del Grupo Parlamentario Popular, anunció que «vamos a introducir también, porque quedaba pendiente como una causa de cancelación de la inscripción registral de los partidos políticos, y por tanto [...] del inicio del procedimiento de extinción de los mismos, el incumplimiento del plazo para convocar los procesos de renovación de los órganos de gobierno y de representación, siempre que ese plazo se haya superado en el doble previsto ya en la norma». 
concurrencia (alternativamente) de alguno de los tres supuestos que enumera, con carácter taxativo, el nuevo art. 12 bis LOPP en su apdo. 1. De hecho, el art. 127 quinquies. 1 a) LJCA exige literalmente que, en la demanda con la que se inicia el procedimiento, se especifique «en cuál o cuáles de los motivos recogidos en el artículo 12 bis.1 de la Ley Orgánica 6/2002, de 27 de junio, de Partidos Políticos, se fundamenta la petición de declaración judicial de extinción».

\section{FALTA DE ADAPTACIÓN DE LOS ESTATUTOS DEL PARTIDO}

Para empezar, el apdo. a) del art. 12 bis.1 LOPP contempla la extinción de un partido político por «no haber adaptado sus estatutos a las leyes que resulten de aplicación en los plazos que éstas prevean en cada caso».

Los estatutos son la norma jurídica que se da el propio partido en virtud de la «libertad organizativa» que reconoce el art. 6 LOPP «con los únicos límites establecidos en el ordenamiento jurídico». Justamente, otra de las novedades de la Ley Orgánica 3/2015 ha sido la regulación del «contenido mínimo que los estatutos han de recoger", cuestión que resuelve el art. 3.2 LOPP mediante un extenso listado que se debe interpretar como un mínimum de carácter imperativo ${ }^{6}$.

Pues bien, en caso de que un partido político no adecúe sus estatutos «a las leyes que resulten de aplicación", dentro de los plazos previstos al efecto ${ }^{7}$, incurrirá en causa de extinción conforme al art. 12 bis.1 a) LOPP.

\section{AUSENCIA DE RENOVACIÓN DE LOS ÓRGANOS DE GOBIERNO Y REPRESENTACIÓN DEL PARTIDO DURANTE OCHO AÑOS}

Tras la Ley Orgánica 3/2015, deviene contenido mínimo de los estatutos de cualquier partido político la regulación de sus «órganos de gobierno y representación». Además, según el art. 3.2 i) LOPP, también deben contemplarse «los plazos para su renovación», la cual «habrá de efectuarse como máximo cada cuatro años».

Así pues, si un partido político no lleva a cabo las actuaciones necesarias para renovar sus órganos de gobierno y representación durante un plazo de

6 Porque, según la prótasis del precepto, «los estatutos de los partidos políticos tendrán, al menos, el siguiente contenido [...]».

7 En el caso de la Ley Orgánica 3/2015, estos plazos vienen fijados por la disposición transitoria primera, que será objeto de nuestro estudio en el epígrafe 5. 
tiempo de más de ocho años — «transcurrido el doble del plazo previsto en el artículo 3.2, letra i)»— incurrirá en la causa de extinción que tipifica el art. 12 bis. 1 b) LOPP. Recuérdese que la renovación de la composición de los órganos de gobierno y representación debe comunicarse, al igual que la modificación de los estatutos, al Registro de Partidos Políticos «en el plazo máximo de tres meses desde dicha modificación y, en todo caso, durante el primer trimestre de cada año", de acuerdo con el art. 3.3 LOPP.

\section{FALTA DE PRESENTACIÓN DE LAS CUENTAS ANUALES DEL PARTIDO}

Por último, el art. 12 bis.1 c) LOPP también contempla como un supuesto de extinción de un partido político la no presentación de «sus cuentas anuales durante 3 ejercicios consecutivos o cuatro alternos, sin perjuicio de las responsabilidades que pudieran derivarse de la falta de presentación de las cuentas».

Se trata, en definitiva, del incumplimiento de la obligación contable que regula el art. 14.Seis LOFPP, de acuerdo con el cual «todos los partidos políticos habrán de remitir las cuentas anuales consolidadas, en las que se detallarán y documentarán sus ingresos y gastos, debidamente formalizadas al Tribunal de Cuentas antes del 30 de junio del año siguiente al que aquellas se refieran». Este deber, que reitera el art. 13.3 LOPP, compete cumplirlo al denominado «responsable de la gestión económico-financiera», una figura creada por la misma Ley Orgánica 3/2015 mediante el nuevo art. 14 bis LOFPP. La presentación de las cuentas anuales se acredita de oficio por el Tribunal de Cuentas mediante el envío de la "justificación» a la que se refiere el art. 14.Siete LOFPP al Registro de Partidos Políticos del Ministerio del Interior y al presidente de la Comisión Mixta para las Relaciones de las Cortes Generales con el susodicho tribunal.

Como advierte el art. 12 bis.1 c) LOPP en su inciso final, la falta de presentación de las cuentas anuales de conformidad con las exigencias del art. 14 LOFPP también generaría responsabilidad en el ámbito de la jurisdicción contable. En concreto, el nuevo art. 17.Dos c) LOFPP tipifica como una infracción muy grave - castigada con una sanción pecuniaria de entre 50000 y 100000 euros por el art. 17 bis.Uno c) — «el incumplimiento durante dos ejercicios consecutivos o tres alternos de la obligación de presentar las cuentas anuales en el plazo previsto en el artículo 14.Seis o la presentación de cuentas incompletas o deficientes que impidan al Tribunal de Cuentas llevar a cabo su cometido fiscalizador ${ }^{8}$.

8 Boletín Oficial de la Cortes Generales, Congreso de los Diputados, núm. A-82-2, 18.12.2014, pp. 157-158. Los proponentes de las enmienda núm. 197 y 198, de las 


\section{EL PROCEDIMIENTO PARA LA DECLARACIÓN JUDICIAL DE EXTINCIÓN DE PARTIDOS POLÍTICOS}

De acuerdo con el art. 12 bis.3 LOPP, «para la declaración judicial de extinción de un partido político se seguirá lo dispuesto en el artículo 127 quinquies de la Ley 29/1998, de 13 de julio, reguladora de la Jurisdicción Contencioso-administrativa».

En efecto, la disposición final segunda de la Ley Orgánica 3/2015 crea en la LJCA un nuevo capítulo $\mathrm{V}$ en su título $\mathrm{V}$, dedicado, como es sabido, a los «procedimientos especiales» para regular el «procedimiento para la declaración judicial de extinción de partidos políticos».

\section{LEGITIMACIÓN ACTIVA}

La declaración judicial de extinción de un partido procede, como queda dicho, en los tres casos de inactividad que enumera el art. 12 bis.1 LOPP siempre y cuando lo solicite a la jurisdicción contencioso-administrativa «el órgano competente, a iniciativa del Registro de Partidos Políticos, de oficio o a instancia de los interesados».

\subsection{El Ministerio del Interior y el Registro de Partidos Políticos}

La primera duda que surge a la hora de interpretar la prótasis de este art. 12 bis. 1 es cuál es realmente el «órgano competente» para instar la extinción de un partido.

Un análisis sistémico de la LOPP parece arrojar una única respuesta posible: el Ministerio del Interior. En este existe, conforme a los arts. 3.4 y 4.2 LOPP, el registro donde deben inscribirse los partidos políticos para adquirir

que trae causa esta infracción y su correspondiente sanción, las justificaron del modo siguiente: «[...] a partir de la entrada en vigor de la Ley Orgánica de control de la actividad económico-financiera de los partidos políticos, el no haber remitido al Registro de Partidos la justificación emitida por el Tribunal de Cuentas de haber presentado sus cuentas anuales durante 3 ejercicios consecutivos o cuatro alternos, será causa que podrá desembocar en una declaración judicial de extinción de un partido. Resulta por ello necesario prever que el incumplimiento de la obligación de presentar las cuentas anuales al Tribunal de Cuentas durante un plazo inferior, sea constitutivo de una conducta merecedora de sanción». 
personalidad jurídica. Y este es, además, el órgano competente para examinar preventivamente el partido que desea ser inscrito en las disyuntivas que contemplan los arts. 5 y 12.3 de la repetidamente aludida LOPP'.

La actuación procesal del Ministerio del Interior se producirá «a iniciativa del Registro de Partidos Políticos $\aleph^{10}$. De hecho, el presidente del Gobierno, al presentar ante el Congreso el Proyecto de Ley Orgánica de Control de la Actividad Económico-financiera de los Partidos Políticos, afirmó textualmente que «el registro de partidos políticos podrá solicitar judicialmente la cancelación de su inscripción ${ }^{11}$. Como venimos diciendo, todas las circunstancias que, conforme al art. 12 bis.1 LOPP, originan la extinción de un partido político se acreditan mediante la información que obra en el Registro de Partidos $^{12}$, lo que justifica que deba ser este el que tenga la iniciativa de solicitar la declaración de tal extinción cuando no cuente con los datos que imperativamente debe comunicarle un determinado partido político. De hecho, como también veremos, es este registro el que debe llevar a cabo el apercibimiento previo a la solicitud de declaración judicial de extinción de un partido.

\subsection{La iniciación «a instancia de los interesados»}

En último lugar, el encabezamiento del art. 12 bis.1 LOPP prevé que el Ministerio del Interior — previa iniciativa del registro aludido — pueda actuar «de oficio o a instancia de los interesados». Mientras que la iniciación de oficio no plantea ulteriores dudas, puesto que permite al Ministerio instar la extinción cuando compruebe la existencia de los presupuestos de la LOPP,

9 Además, según el art. 6.1 del Real Decreto 1823/2011, de 21 de diciembre, por el que se reestructuran los departamentos ministeriales, le corresponde al Ministerio del Interior la "promoción de las condiciones para el ejercicio de los derechos fundamentales», entre los que se incluyen tanto el de asociación como el de participación política, de conformidad con los arts. 22 y 23.1 de la Constitución.

10 La gestión de este registro corresponde a la Dirección General de Política Interior, radicada orgánicamente en la Subsecretaría de Interior del Ministerio de referencia. Véanse el art. 5.B) 2. ${ }^{\circ}$ del Real Decreto 1887/2011, de 30 de diciembre, y los arts. 7.2 c) y $9.2 \mathrm{f}$ ) del Real Decreto 400/2012, de 17 de febrero, por el que se desarrolla la estructura orgánica básica del Ministerio del Interior.

11 Diario de Sesiones, Congreso de los Diputados (Pleno), núm. 245, 27.11.2014, p. 7.

12 En los supuestos de los apdos. a) y b) del art. 12 bis.1 LOPP, la comunicación del partido al Registro debe efectuarse por imperativo de su art. 3.3, mientras que en el del apdo. c) la remisión se formaliza directamente por el Tribunal de Cuentas conforme al art. 14.Siete LOFPP. 
para colegir la referencia a los «interesados» debemos remitirnos a la legislación del procedimiento administrativo general.

En concreto, el art. 4 de la Ley 39/2015, de 1 de octubre, del Procedimiento Administrativo Común de las Administraciones Públicas, concede la condición de interesados a quienes promuevan el procedimiento administrativo «como titulares de derechos o intereses legítimos individuales o colectivos» [apdo. a)].

En su reciente Sentencia de 15 de marzo de 2013, la Sala Tercera del Tribunal Supremo ha declarado — evocando su jurisprudencia histórica- los siguientes:

Interés legítimo [es] el que tienen aquellas personas que por razón de la situación objetiva en que se encuentran, por una circunstancia de carácter personal, o por ser los destinatarios de una regulación sectorial, son titulares de un interés propio, distinto del de cualquier ciudadano, de que los poderes públicos actúen de acuerdo con el ordenamiento cuando con motivo de la persecución de fines de interés general, inciden en el ámbito de tal interés propio, aun cuando la actuación de que se trate no les ocasione en concreto un beneficio o un servicio inmediato [...] para que exista el interés basta con que el éxito de la acción represente para el recurrente un beneficio material o jurídico o, por el contrario, que el mantenimiento de la situación creada o que pudiera crear el acto combatido le origine un perjuicio, incluso aunque tales beneficio o perjuicio se produzcan por vía indirecta o refleja ${ }^{13}$.

A la luz de esta doctrina, en el caso que nos ocupa, el primer titular de un interés legítimo sería aquel partido político que desee extinguirse. Se trataría de una situación paradójica, es cierto, pero no por ello imposible, puesto que el partido podría tomar la decisión de solicitar su propia extinción sin alterar las circunstancias de inactividad que tipifica el art. 12 bis.1 LOPP. El apdo. b) de este precepto prevé como motivo de extinción el «no haber convocado el órgano competente para la renovación de los órganos de gobierno y representación", por lo que una convocatoria del órgano en cuestión cuyo orden del día fuera solicitar la extinción del partido sería compatible con su concurrencia. En efecto, como ya hemos visto, lo que determina la inactividad causante de extinción no es la falta de reunión del órgano de gobierno y representación, sino la ausencia de su renovación periódica. Ello sin perjuicio, como es obvio, de que el partido pudiera alegar cualquiera de los otros dos motivos que enumera el propio art. 12 bis.1 LOPP. Pese a todo ello, no podemos olvidar la escasa virtualidad práctica

13 Tribunal Supremo, Sala de lo Contencioso-administrativo, Sección 3. a, Sentencia de 15 de marzo de 2013 (recurso de casación núm. 4408/2009), fundamento jurídico 3.. 
de esta hipótesis por cuanto la propia LOPP reconoce la capacidad de cualquier partido para autodisolverse, conforme a sus arts. 3.2 p) y 10.1, pudiendo conseguir por esta vía el mismo objetivo — la cesación de su vida jurídica - de un modo mucho más sencillo y, sobre todo, autónomo.

Pero también cabría encontrar otros interesados para instar el proceso judicial que estamos estudiando: sería el caso, por ejemplo, de aquel partido político que desease adoptar una denominación coincidente o semejante con la de un partido previamente inscrito que se encontrase en situación de inactividad conforme al art. 12 bis.1 LOPP. Al verse entorpecida su inscripción al Registro por la circunstancia que prevé el segundo párrafo del art. 3.1 $\mathrm{LOPP}^{14}$, el partido en cuestión tendría realmente un interés legítimo para que fuese declarado extinguido el otro partido y, de este modo, poder adoptar la denominación controvertida. La correcta justificación de tal interés legítimo sería transcendental porque en la LOPP no se reconoce la acción popular, cuyo ejercicio ante la jurisdicción contenciosa-administrativa se permite solo conforme al art. $19.1 \mathrm{~h}$ ) LJCA «en los casos expresamente previstos por las Leyes».

Todo lo dicho hasta el momento no puede hacernos olvidar, empero, la dicción literal del art. 12 bis.1 LOPP: «el órgano competente, a iniciativa del Registro de Partidos Políticos, de oficio o a instancia de los interesados solicitará a la Jurisdicción contencioso-administrativa, la declaración judicial de extinción de un partido político». La legitimación activa para promover el proceso que regula el art. 127 quinquies LJCA se atribuye, únicamente y exclusivamente, al Ministerio del Interior, de modo que el papel de los interesados se reduce a solicitar a este "órgano competente» que inicie las actuaciones procesales correspondientes.

\subsection{El Ministerio Fiscal}

Finalmente, debe resaltarse la necesaria participación de la Fiscalía en el procedimiento de declaración de extinción de un partido político en virtud del art. 127 quinquies.2 LJCA. Esta disposición prevé que «el Ministerio Fiscal será parte del proceso», lo que no le faculta para iniciarlo — a diferencia de

14 Según esta disposición, la denominación de un partido político «no podrá coincidir, asemejarse o identificarse, aun fonéticamente, con la de ningún otro partido previamente inscrito en el Registro, con la de algún partido integrante, como resultado de una fusión, de un partido inscrito cuando ello se encuentre acreditado por cualquier medio de prueba válido en derecho, o con la de algún partido declarado ilegal, disuelto o suspendido por decisión judicial». 
lo que ocurre con la declaración de ilegalidad, según el art. 11.1 LOPP—, sino solo para participar en él.

Algo muy congruente con la función del ministerio público de «velar por el respeto de las instituciones constitucionales y de los derechos fundamentales y libertades públicas con cuantas actuaciones exija su defensa», de conformidad con el art. 3.3 de su Estatuto Orgánico, aprobado por la Ley 50/1981, de 30 de diciembre.

\section{2. ÓRGANO JURISDICCIONAL COMPETENTE}

La disposición final segunda de la Ley Orgánica 3/2015 modifica dos preceptos de la LJCA para asignar a los órganos de la jurisdicción contenciosa-administrativa el conocimiento del procedimiento para la declaración judicial de extinción de partidos políticos. De este modo, se da cumplimiento a lo estipulado por el art. 22.4 de la Constitución, de acuerdo con el cual «las asociaciones solo podrán ser disueltas o suspendidas en sus actividades en virtud de resolución judicial motivada». Recordemos que este precepto dio lugar a que el Tribunal Constitucional declarase, en su muy primeriza Sentencia núm. 3/1981, de 2 de febrero, que «al Poder Judicial, y solo a este, encomienda la Constitución y también la legislación ordinaria la función de pronunciarse sobre la legalidad de un partido político» ${ }^{15}$.

Además, como la consecuencia de la extinción de un partido es justamente la cancelación de su inscripción en el Registro, no podía ser sino el orden jurisdiccional contencioso-administrativo el competente para conocer de este procedimiento en virtud de la regla general del art. 5.5 LOPP, según el cual «las actuaciones administrativas relacionadas con la inscripción del partido político podrán recurrirse ante la jurisdicción contencioso-administrativa» ${ }^{16}$.

15 Tribunal Constitucional, Sala Primera, Sentencia núm. 3/1981, de 2 de febrero (recurso de amparo núm. 98/1980), fundamento jurídico 9.․

16 El capítulo V de la exposición de motivos de la LOPP incluye la siguiente la reflexión sobre esta cuestión: «[...] resulta notorio que la jurisprudencia ha clarificado ya los supuestos en que procede el acceso al orden jurisdiccional civil, en relación con las pretensiones derivadas del tráfico jurídico privado de los partidos o formuladas por los afiliados sobre su funcionamiento interno, o en los que es competente el orden jurisdiccional contencioso-administrativo en relación con las cuestiones que se susciten en los procedimientos administrativos derivados de la Ley. Del mismo modo, el Código Penal y la Ley de Enjuiciamiento Criminal aclaran hoy los supuestos en que procede la disolución 
En concreto, el novísimo art. 9.3 LJCA atribuye estos asuntos a los Juzgados Centrales de lo Contencioso-Administrativo ${ }^{17}$.

\section{EL APERCIBIMIENTO DEL ART. 12 BIS.2 LOPP}

En virtud del art 12 bis. 2 LOPP, antes de iniciarse la tramitación propiamente dicha de la declaración judicial de extinción, es preciso que el Registro de Partidos Políticos lleve a cabo un apercibimiento al partido de que se trate «para que, en el plazo de 6 meses, proceda a justificar bien que ha realizado la adaptación de sus estatutos a la ley, bien que ha renovado sus órganos de gobierno y representación, bien que ha presentado las cuentas anuales de todos los ejercicios que tenga pendientes, o en su caso, todo lo anterior». Es decir, se concede una nueva oportunidad al partido para que argumente que no se hallan en ninguna de las circunstancias del art. 12 bis.1.

Dispone, finalmente, el art. 12 bis. 2 LOPP que, «transcurrido este plazo [de seis meses] sin que el partido político haya realizado las actuaciones descritas, el Registro de Partidos iniciará el procedimiento» del art. 127 quinquies LJCA.

Parece claro que este apercibimiento debería servir solamente para que el partido político «justifique» que ha realizado en tiempo y forma las conductas que enumera el art. 12 bis.1 LOPP efectuando la oportuna comunicación al Registro en medio año. Desde esta perspectiva, el trámite del art. 12 bis.2 LOPP no concedería al partido un tiempo adicional para llevar a cabo unas actuaciones cuyo término legal ya habría expirado al tiempo de hacerse el apercibimiento. Debe rechazarse, pues, que este pueda permitir al partido político actualizar sus estatutos, renovar sus órganos de gobierno o representación y/o presentar sus cuentas anuales una vez concluidos los plazos previstos específicamente para ello por el art. 12 bis.1 LOPP.

\section{TRAMITACIÓN PROCESAL}

De conformidad con el art. 127 quinquies.1 LJCA, «el procedimiento para la declaración judicial de extinción de un partido político se regirá por lo

o suspensión de un partido por el orden jurisdiccional penal y el procedimiento a seguir para que una decisión tan relevante se produzca con todas las garantías».

17 Véase también, en el mismo sentido, el art. 90.6 de la Ley Orgánica 1/1985, de 1 de julio, del Poder Judicial, añadido por la disposición final primera de la Ley Orgánica 3/2015. 
dispuesto en el artículo 78», o sea, se ventilará por el cauce del denominado "procedimiento abreviado». Deberán respetarse, sin embargo, las siguientes dos especialidades:

a) el plazo general de dos meses para la interposición de la demanda que prevé el art. 46.1 LJCA se contará, en este caso, «a partir del día siguiente al vencimiento del plazo señalado en el artículo 12 bis. 2 de la misma ley [en alusión a la LOPP]». Por lo tanto, el Ministerio del Interior podrá interponer la demanda de extinción durante los dos meses posteriores a la finalización del período de medio año que se abre con la formulación del apercibimiento que contempla el aludido art. 12 bis. 2 LOPP.

b) Además, en la demanda en cuestión, como queda dicho, «deberá especificarse en cuál o cuáles de los motivos recogidos en el artículo 12 bis. 1 de la Ley Orgánica 6/2002, de 27 de junio, de Partidos Políticos, se fundamenta la petición de declaración judicial de extinción».

La principal característica del procedimiento contencioso-administrativo abreviado es la ausencia de contestación escrita a la demanda, por lo que la parte demandada — el partido cuya extinción se solicita, en este caso- formula sus alegaciones directamente durante la vista, de conformidad con el art. 78.7 LJCA. Parece claro que este diseño obedece a un elemental criterio de economía procesal en previsión de que el partido demandado, precisamente por estar inactivo, no comparezca o, si lo hace, apenas pueda tener argumentos para desplegar una verdadera estrategia de defensa. Entonces, la principal dificultad de la tramitación de este proceso judicial estriba en la prueba de los motivos de extinción del partido político. Solo el Registro de Partidos Políticos del Ministerio del Interior está capacitado para demostrar la inactividad del partido mediante la constatación fehaciente de que no se han inscrito los actos a los que se refieren los tres apdos. del art. 12 bis.1 LOPP. Será preciso, pues, para que el Ministerio pueda instar válidamente la declaración de extinción, que el Registro expida una verdadera certificación negativa ${ }^{18}$ sobre el extremo que corresponda.

18 El ordenamiento jurídico español contempla varios supuestos en los que se prevé la expedición de una certificación registral negativa. Uno de los más recientes es el que establece el art. 9.3 del Real Decreto 1110/2015, de 11 de diciembre, por el que se regula el Registro Central de Delincuentes Sexuales, pero también pueden ser mencionados el art. 409.1 del Real Decreto 1784/1996, de 19 de julio, por el que se aprueba el Reglamento del Registro Mercantil o el art. 33.1 del Real Decreto 


\section{EFECTOS DE LA SENTENCIA}

La sentencia - que tendrá que dictarse en un plazo de diez días desde la celebración de la vista en aplicación del art. 78.20 LJCA — podrá declarar extinguido el partido o, por el contrario, podrá desestimar la demanda y su petición de extinción.

$\mathrm{Ni}$ el art. 127 quinquies LJCA ni el art. 12 bis LOPP aluden, en ningún momento, a los recursos que pueden o no pueden interponerse contra esta sentencia, por lo que cabe entenderla sometida al régimen general de la LJCA, esto es, recurso de apelación ante la Sala de lo Contencioso-Administrativo de la Audiencia Nacional, conforme a los arts. 81.1 y 11.2; y, en su caso, recurso de casación ante la Sala Tercera del Tribunal Supremo.

Una vez se firme la sentencia que, efectivamente, declare la extinción de un partido político, en virtud del apdo. c) del art. 127 quinquies.1 de LJCA, «será notificada al registro para que este proceda a la cancelación de la inscripción». En sentido análogo, el art. 12 bis.4 LOPP prevé que «la declaración judicial de extinción surtirá efectos desde su anotación en el Registro de Partidos Políticos, previa notificación efectuada por el órgano judicial».

Por imperativo del art. 4.4 LOPP, el acceso de la sentencia al Registro tendrá como consecuencia final y definitiva del procedimiento que venimos explicando la cesación de los efectos de la inscripción del partido. El capítulo III de la exposición de motivos de la propia LOPP explica que «la inscripción en el Registro de Partidos Políticos del acta fundacional y de los estatutos confiere al partido personalidad jurídica, hace pública la constitución y los estatutos del mismo, vincula a los poderes públicos, y es garantía tanto para los terceros que se relacionan con el partido como para sus propios miembros». Por lo tanto, la cancelación de la inscripción finaliza absolutamente toda la vida pública y privada del partido: este pierde su personalidad jurídica y sus estatutos son despojados de cualquier vigor.

Cabe preguntarse si resultaría de aplicación al partido extinguido el art. 12 LOPP, relativo a los efectos de la disolución judicial de un partido. La respuesta podría ser afirmativa, por una mera razón de analogía, si bien con matices: «el cese inmediato de toda la actividad» es un efecto que puede predicarse tanto del partido disuelto como del extinguido, pero las consecuencias incluso penales a las que se refieren algunos de los apdos. del propio art. 12 no parece que puedan extenderse a los supuestos de extinción. En algunos casos, por el contrario, sí que será posible o necesaria «la apertura de un proceso de

136/2002, de 1 de febrero, por el que se aprueba el Reglamento del Registro de Sociedades Cooperativas, entre otros. 
liquidación patrimonial», por lo que pueden ser útiles las dos previsiones del art. 12 bis.1 c) LOPP: el nombramiento de los liquidadores por el propio órgano jurisdiccional encargado de declarar la extinción y la destinación del patrimonio neto resultante por el Tesoro a «actividades de interés social o humanitario».

\section{EL ART. 12 BIS LOPP EN EL TIEMPO: ANÁLISIS DE LA DISPOSICIÓN TRANSITORIA PRIMERA DE LA LEY ORGÁNICA 3/2015}

La disposición transitoria primera de la Ley Orgánica 3/2015 «concede — según leemos en el preámbulo- a los partidos inscritos en el Registro un plazo para adaptar sus estatutos al nuevo contenido mínimo previsto en la LOPP, además del apercibimiento de que, en caso de incumplimiento de esta obligación, se pondrá en marcha el procedimiento de declaración judicial de extinción».

Estas adaptaciones deberían haberse efectuado, según el apdo. 1 de la referida disposición transitoria, en la "primera reunión» celebrada por los «órganos [del partido político] que tengan la competencia para llevar a cabo tal modificación» después del 1 de abril de 2015, fecha de entrada en vigor de la Ley Orgánica 3/2015 según su disposición final décima. La misma disposición transitoria también indica que, «una vez efectuada la adaptación estatutaria, habrán de comunicárselo al Registro de Partidos Políticos, al que facilitarán el certificado correspondiente y los nuevos estatutos» ${ }^{19}$. Se trata, sin embargo, de unas reglas transitorias cuya eficacia práctica parece claro que será limitada por cuanto en el fondo lo relevante va a ser que la adaptación de los estatutos y su comunicación al Registro «en todo caso» se hayan realizado antes del 1 de abril de 2018, que es cuando se cumplen «tres años desde la entrada en vigor» de la Ley Orgánica 3/2015. En caso contrario, advierte la disposición transitoria primera en su apdo. 1, «se pondrá en marcha el procedimiento previsto en el art. 12 bis $»^{20}$.

19 De hecho, como ya queda apuntado, la comunicación al Registro de «cualquier modificación» de los estatutos pasa a ser una obligación general que todos los partidos deben cumplir, conforme al art. 3.3 LOPP, «en el plazo máximo de tres meses desde dicha modificación y, en todo caso, durante el primer trimestre de cada año». Además, se exige que publiquen tales cambios en su página web.

20 El Proyecto de Ley presentado en febrero de 2014 por el Gobierno que - como hemos dicho - todavía no contemplaba añadir a la LOPP un art. 12 bis, incluía una única disposición transitoria cuyo apdo. 1 contemplaba la siguiente 
El apdo. 2 de la disposición transitoria, que venimos comentando, regula la situación en la que quedan aquellos partidos políticos cuyos estatutos no deben ser cambiados para adecuarlos al nuevo art. 3.2 LOPP. En tal caso, «los partidos deberán comunicar al Registro que no es necesaria su modificación por ajustarse a la misma [LOPP]». Esta comunicación deberá haberse cursado antes del 1 de abril de 2018, dado que en lo que al plazo se refiere el apdo. dos de la disposición transitoria primera se remite a su apdo. 1.

Queda claro, así pues, que los dos preceptos que se acaban de estudiar complementan la causa de extinción del art. 12 bis.1 a) LOPP: un partido se hallará en situación de inactividad — con las consecuencias que ello acarreasi no ha adaptado sus estatutos a la Ley Orgánica 3/2015 y lo ha comunicado al Registro de Partidos Políticos antes del 1 de abril de $2018^{21}$. Aunque no sea claro del todo, parece razonable — dada la dicción literal del apdo. 2 de la disposición transitoria primera, que empieza con el adverbio asimismo - aplicar una idéntica consecuencia de declaración de inactividad y extinción judicial a aquellos partidos que, antes de la misma fecha, no hayan comunicado al Registro la falta de necesidad de modificar sus estatutos.

consecuencia para los partidos políticos que no procediesen con sus estatutos del modo que queda explicado: "[...] la autoridad encargada del mismo [Registro] apercibirá al partido político para que cumpla con dicha obligación, sin perjuicio de lo cual no se procederá a realizar inscripción alguna a solicitud del partido político en dicho Registro en tanto por el mismo no se lleve a cabo la adaptación y comunicación citada». La enmienda núm. 209 del Grupo Parlamentario Popular serviría para sustituir esta fórmula por la reconducción al procedimiento del art. 12 bis, que es la regulación vigente, en aras a una razón de "coherencia» perfectamente comprensible. Véase, respectivamente, el Boletín Oficial de la Cortes Generales, Congreso de los Diputados, núm. A-82-1, 28.02.2014, p. 17; y núm. A-82-2, 18.12.2014, p. 165.

21 Retomando lo que decíamos al glosar el contenido del apdo. 1 de la disposición transitoria primera, si bien es cierto que esta exige con toda claridad que la modificación estatutaria se efectúe en la primera reunión del órgano competente que se celebre después el 1 de abril de 2015, no parece que pudiera llegar a considerarse inactivo un partido político por haber acometido el cambio de sus estatutos después de tal fecha, pero antes del 1 de abril de 2018. En efecto, el último inciso del precepto en cuestión es igualmente nítido en el sentido de que el procedimiento del art. 12 bis LOPP solo se pondrá en marcha «transcurridos en todo caso tres años desde la entrada en vigor de esta ley sin que se haya producido dicha adaptación y comunicación al Registro». Por ello, se debe entender que incumplir el calendario prevenido por el apdo. 2 de la disposición transitoria primera tendría consecuencias únicamente en caso de que se rebasara la fecha límite del 1 de abril de 2018. 
Bien al contrario, la Ley Orgánica 3/2015 no contempla reglas transitorias para la aplicación de los otros dos motivos de extinción enumerados por el art. 12 bis.1 LOPP. Ante este vacío normativo surge la duda sobre si sería posible dotar de efectos retroactivos las nuevas previsiones de la LOPP. ¿Podría promoverse la extinción judicial de un partido que, al entrar en vigor la Ley Orgánica 3/2015, ya llevara acumulados ocho años sin renovar sus órganos de gobierno y representación o el cómputo de este período de tiempo debe hacerse ab initio desde la susodicha entrada en vigor? ¿Los tres ejercicios consecutivos o los cuatro ejercicios alternos sin presentar debidamente las cuentas anuales que dan lugar a la extinción de un partido conforme al art. 12 bis.1 c) LOPP, tienen que contarse desde el 1 de abril de 2015 o pueden tenerse en cuenta ejercicios económicos anteriores a tal fecha?

En una recientísima Sentencia de 30 de noviembre de 2016, la Sala Tercera del Tribunal Supremo ha recordado, citando su jurisprudencia precedente, la «equivocidad» del término «retroactividad», que «ha planteado desde tiempo inmemorial problemas de dogmática jurídica bien conocidos» hasta el punto de que "fácilmente» un «debate» sobre el particular "puede convertirse en una serie de disquisiciones más o menos interesadas sobre una noción jurídica respecto de la cual cada interlocutor parece hablar de realidades diferentes ${ }^{22}$. Pese a ello, del escaso ámbito de claridad que existe en esta disciplina podemos deducir dos criterios que nos sirven para resolver el conflicto sobre la eventual aplicación retroactiva del novísimo art. 12 bis LOPP. De entrada, el art. 2.3 del Código Civil señala que «las leyes no tendrán efecto retroactivo si no dispusieren lo contrario", de modo que para que una ley se aplique ex tunc «es preciso - ha recodado la Sala Primera del mismo Alto Tribunalque esta así lo disponga». La Ley Orgánica 3/2005 contiene un régimen de transitoriedad, como hemos visto, pero no incluye ninguna referencia para su eventual aplicación retroactiva. Es cierto, como ha afirmado la misma Sala Primera, que, «a falta de previsión expresa, jurisprudencia y doctrina admiten también la retroactividad que resulta tácitamente de la norma», pero tal posibilidad choca con el escollo del art. 9.3 de la Constitución, uno de cuyos incisos «proscribe de modo absoluto la aplicación retroactiva de una norma posterior restrictiva de derechos individuales $»^{23}$. En el caso que nos ocupa, el

22 Tribunal Supremo, Sala de lo Contencioso-administrativo, Sección 3. a, Sentencia de 30 de noviembre de 2016 (recurso contencioso-administrativo núm. 542/2014), fundamento jurídico $4 .^{\circ}$, apdo. d).

23 Tribunal Supremo, Sala de lo Civil, Sección 1. a, Sentencia de 20 de abril de 2009 (recurso de casación núm. 490/2005), fundamento jurídico 3.․ Véase también, sobre este último punto, la Sentencia del Tribunal Constitucional núm. 270/2015, 
art. 12 bis LOPP constituye una restricción al derecho fundamental de asociación, como hemos visto, por lo que su aplicación retroactiva parece claro que es legalmente inviable.

Como consecuencia de todo ello, y pese a que la voluntad expresa del legislador fue que la Ley Orgánica 3/2015 sirviese para expurgar los «aproximadamente 4200 partidos inscritos en el Registro, en una gran mayoría inactivos», podemos afirmar que el procedimiento para la declaración de extinción de un partido político está llamado a permanecer en hibernación hasta la segunda mitad de 2017. Se trata del momento en el cual un partido ya podrá llevar acumulados tres ejercicios consecutivos sin presentar sus cuentas anua$\operatorname{les}^{24} \mathrm{y}$ hallarse incurso, por ello, en la causa de extinción del art. 12 bis.1 c) LOPP. Asimismo, como hemos visto, a principios de 2018 acabará el plazo para adaptar los estatutos de los partidos a la Ley Orgánica 3/2015, por lo que también devendrá aplicable el motivo del art. 12 bis.1 a) de la misma LOPP.

\section{CONCLUSIONES}

Con la laudable voluntad de mejorar el funcionamiento del Registro de Partidos Políticos, una institución esencial para la debida garantía del pluralismo político del Estado español (arts. 1.1 y 6 de la Constitución), la Ley Orgánica 3/3015, de 30 de marzo, ha creado un procedimiento para la declaración judicial de extinción de partidos políticos.

Tal extinción procede cuando se acredite la inactividad del partido. El apdo. 1 del novísimo art. 12 bis LOPP, sin embargo, circunscribe tal constatación a tres motivos muy concretos, lo que tal vez acabe siendo un impedimento para que el nuevo procedimiento contencioso-administrativo especial sirva realmente para depurar el Registro de Partidos Políticos. Cualquier partido que se halle en las circunstancias del art. 12 bis.1 LOPP está inactivo, como es obvio, pero podría haber otros que sin cumplir con tales motivos también estén en una verdadera situación de inactividad. Solo la aplicación

de 17 de diciembre (recurso de inconstitucionalidad núm. 5347/2013), fundamento jurídico 7. ${ }^{\circ}$, apdo. c): "[...] el límite expreso de la retroactividad in peius de las leyes que el art. 9.3 CE garantiza se circunscribe a las leyes ex post facto sancionadoras o restrictivas de derechos individuales».

24 Así se deduce del ya aludido art. 14.Seis LOFPP. El supuesto planteado consistiría en que un partido hubiese dejado de presentar consecutivamente las cuentas de los ejercicios económicos 2014 (30 de junio de 2015), 2015 (30 de junio de 2016) y 2016 (30 de junio de 2017). 
práctica del art. 12 bis LOPP y de su correlato procesal —el art. 127 quinquies LJCA — permitirá resolver estas dudas y, al mismo tiempo, saber si las hipótesis que se han trazado en este trabajo son factibles en la realidad forense.

La atribución del conocimiento de todos estos asuntos a los Juzgados Centrales de lo Contencioso-Administrativo evita convertir este procedimiento en una mera cuestión gubernativa del Registro de Partidos Políticos, algo que habría sido gravemente contrario al art. 22.4 de la Constitución, y a su vez garantiza la unidad de criterio, algo muy deseable en una materia tan sensible como ésta. La jurisprudencia de estos juzgados y de la Sala de lo Contencioso-Administrativo de la Audiencia Nacional será determinante para resolver las dudas que plantea esta inadvertida novedad de la Ley Orgánica 3/2015, de 30 de marzo.

\section{Bibliografía}

Bautista Plaza, D. (2006). La función constitucional de los partidos políticos. Granada: Comares.

Martínez Cuevas, M. D. (2006). Régimen jurídico de los partidos políticos. Madrid, Marcial Pons, 2006.

Montilla Martos, J. A. (ed.) (2004). La prohibición de partidos políticos. Almería, Universidad de Almería.

Pérez-Moreno Agapito, M. (2007). La disolución de partidos politicos por actividades antidemocráticas. Valladolid: Lex Nova.

Sánchez Muñoz, O. (2015). La insuficiente reforma de la financiación de los partidos: la necesidad de un cambio de modelo. Revista Española de Derecho Constitucional, 104, 49-82. Disponible en: http://dx.doi.org/10.18042/cepc/redc.104.02.

Tajadura Tejada, J. (2004). Partidos políticos y Constitución: un estudio de la LO 6/2002, de 27 de junio, de Partidos Políticos, y de la STC 48/2003, de 12 de marzo. Madrid: Civitas. 